\title{
Repeat Ultrasonographic Examinations Reveal Accessory Spleen in a Case with Relapse ITP
}

\author{
Ahmet Sarici", Ayshe Slocum, Hilal Er Ulubaba, Mehmet Hanifi Kandemir, Mehmet \\ Ali Erkurt, Emin Kaya and irfan Kuku
}

Department of Haematology, Turgut Özal Medical Center, Faculty of Medicine, Inönü University, Turkey

*Corresponding author: Ahmet Sarici, Department of Haematology, Turgut Özal Medical Center, Faculty of Medicine, inönü University, Turkey

\author{
Keywords \\ Primary immune thrombocytopenia, Accessory spleen, Sple- \\ nectomy
}

\section{Introduction}

Primary immune thrombocytopenia (ITP) is an autoimmune disease characterized by isolated thrombocytopenia (<100,000/microliters). The pathogenesis of (ITP) is related to a combination of increased platelet destruction and impaired platelet production caused principally by antiplatelet autoantibodies [1]. ITP is a commonly acquired bleeding disorder which often is a chronic disease in adults. The clinical manifestations of ITP are all mostly related to bleeding and/or thrombocytopenia; fatigue occurs in some patients. In patients newly diagnosed with ITP, treatment is initiated if thrombocyte count is $<30,000 /$ microliters or if bleeding is present. The goal of (ITP) therapy is to provide a safe platelet count to prevent clinically significant bleeding, rather than to normalize the platelet count. Corticosteroids are the first treatment option. For all patients with persistent ITP who have experienced clinically important bleeding despite first-line therapy with glucocorticoids, second-line therapy should be evaluated. Second-line treatment is initiated in unresponsive patients and/or in the case of relapse ITP [2]. Splenectomy, rituximab and thrombopoietin receptor agonists (TPO-RAs) currently make up the most effective second-line treatments and splenectomy and rituximab are both associated with durable remissions off-treatment. One of the causes of relapse after splenectomy in patients with ITP is the presence of an accessory spleen. Herein, we present a patient who relapsed 3 months after splenectomy and whose accessory spleen was detected 6 years post-splenectomy and at the third abdominal ultrasonography (USG) examination. We aimed to emphasize the importance of insisting on splenic investigation in patients with ITP who have relapsed post-splenectomy.

\section{Case Report}

A 45-year-old female patient was evaluated in our outpatient clinic with a complaint of recurrent bruising on her legs. The patient's initial complete blood count revealed a hemoglobin count of $14.4 \mathrm{~g} / \mathrm{dL}$, a white blood cell count of $11.900 \times 10^{9} /$ liters and a platelet count of $5.000 \times 10^{9} /$ liters. Thrombocytopenia was confirmed by peripheral blood smear. Other causes of secondary thrombocytopenia were excluded and the patient was diagnosed with immune thrombocytopenia. On physical examination, there were no significant findings except for petechiae and ecchymosis on both lower extremities. The patient was prescribed $1 \mathrm{mg} / \mathrm{kg}$ prednisone and partial response to steroid treatment was obtained. The patient ultimately underwent a splenectomy because of the loss of partial response upon follow-up as she demonstrated irregular control thrombocyte measurements. Splenectomy was performed 15 months after the initial diagnosis and a partial response to splenectomy lasting about 3.5 months was observed. A pathological examination of splenectomy material demonstrated

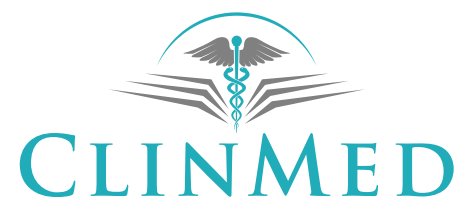

INTERNATIONAL LIBRARY

Citation: Sarici A, Slocum A, Ulubaba HE, Kandemir MH, Erkurt MA, et al. (2019) Repeat Ultrasonographic Examinations Reveal Accessory Spleen in a Case with Relapse ITP. Int J Blood Res Disord 6:044. doi.org/10.23937/2469-5696/1410044

Accepted: August 07, 2019: Published: August 09, 2019

Copyright: (C) 2019 Sarici A, et al. This is an open-access article distributed under the terms of the Creative Commons Attribution License, which permits unrestricted use, distribution, and reproduction in any medium, provided the original author and source are credited. 


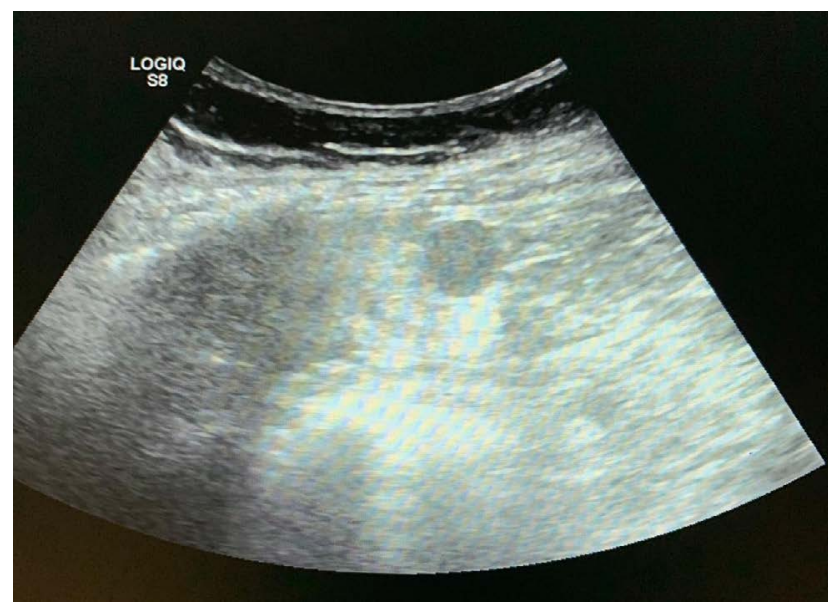

Figure 1: Ultrasonography (USG) revealing accessry spleen.

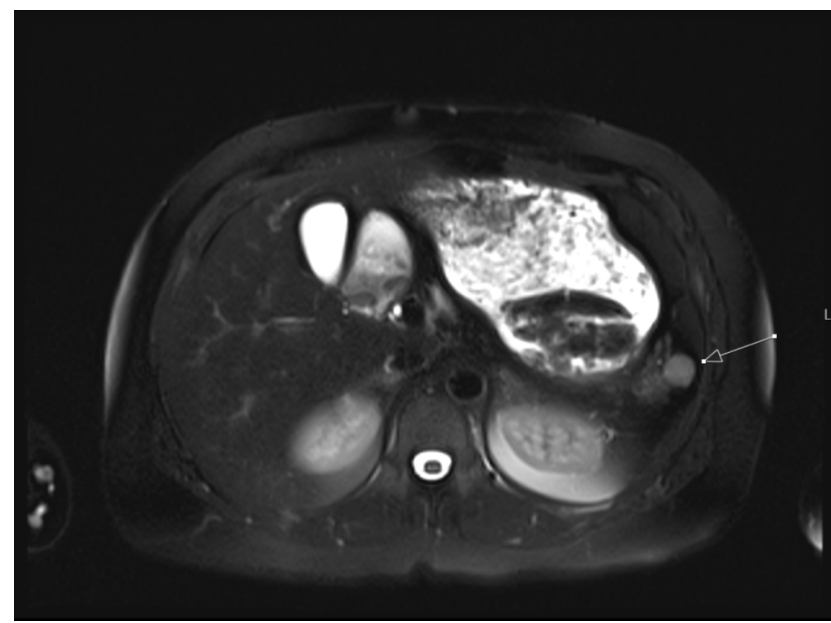

Figure 2: Magnetic resonance image (MRI) demonstarting accessory spleen (arrow).

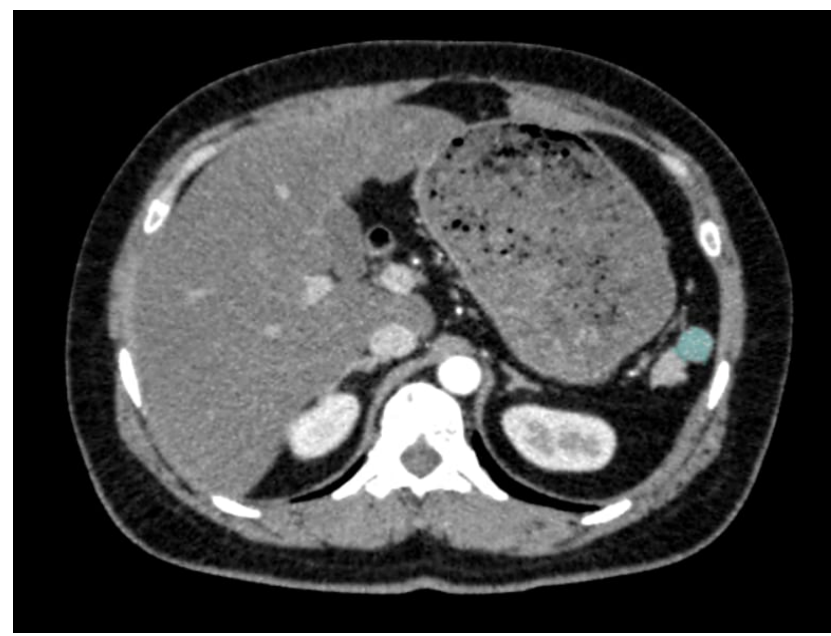

Figure 3: Computed tomography (CT) demonstrating accessory spleen.

marked lymphoid hyperplasia in white pulp and prominence of a large number of macrophages with phagocytosed erythrocytes in the sinusoids of the red pulp, in support of our diagnosis of ITP. Thrombocytopenia repeated 3.5 months after splenectomy and prednisone and azathiopurine were given for 9 months. The patient was then followed for six years without treatment. However, thrombocytopenia repeated after 6 years. The patient was once again prescribed prednisone $1 \mathrm{mg} / \mathrm{kg} /$ day in addition to eltombopag $25 \mathrm{mg} /$ day.

Abdominal USG evaluations performed 6 months post-splenectomy and later 6 years post-splenectomy, did not report presence of an accessory spleen. The third and final abdominal USG of the patient with refractory thrombocytopenia revealed an accessory spleen measuring $1.5 \mathrm{~cm}$ (Figure 1). Computed tomography (CT) as well as a magnetic resonance imaging (MRI) performed following the abdominal ultrasonography also confirmed presence of an accessory spleen (Figure 2 and Figure 3). In the case of the patient being presented, the accessory spleen detected in USG, MRI and CT was not observed in $3 \mathrm{mCl}$ Tc99m-sulfide colloid scintigraphy. A second splenectomy was planned for removal of the accessory spleen.

\section{Conclusion}

The aim of treatment in patients with primary immune thrombocytopenia (ITP) is to obtain a safe platelet count to prevent clinically significant bleeding (major bleeding) rather than normalizing the platelet count $[3,4]$. In light of this information, treatment indications for newly diagnosed ITP patients include, I) Thrombocyte counts below 30,000/microL and II) Platelet counts above $30,000 / \mathrm{microL}$ in correlation with clinically significant bleeding.

Corticosteroids make-up the first-line treatment of patients newly diagnosed with ITP. Intravenous immunoglobulin and Anti-(Rh) D are other treatment options. In primary care, standard dose prednisone or methylprednisolone (1-2 mg/kg/day), or high-dose dexamethasone (40 mg/day) is administered as corticosteroid therapy. $65-85 \%$ of newly diagnosed ITP patients respond to standard dose prednisone or methylprednisolone [5]. Recently, studies comparing the efficacy of dexamethasone and prednisone treatments have been increasing. These studies have reported that cases diagnosed with ITP respond earlier to dexamethasone treatment and that response rates are higher than those obtained using prednisone $[5,6]$. However, in a meta-analysis published in 2016, dexamethasone treatment has not been shown to be superior to prednisolone therapy in the long-term and in contrast to the early stages of treatment [7]. Most newly diagnosed ITP patients who respond to corticosteroid treatment have long-term relapse. In patients with ITP who have no response to relapse and/or relapse to first-line treatment, second-line treatment is initiated. Splenectomy, rituximab and thrombopoietin receptor agonists are the most important current second-line treatments.

Approximately $80 \%$ of ITP patients respond to splenectomy and in $60-65 \%$ of patients this response con- 
tinues for many years $[8,9]$. On the other hand, nearly $15 \%$ of ITP patients that respond to splenectomy develop relapse after splenectomy [10]. As in the case of our patient, most of relapses develop shortly after splenectomy $[10,11]$. However, it is reported that relapse may occur up to 30 years post-splenectomy [12]. One of the major causes of relapse post-splenectomy is the presence of an accessory spleen. It is for this reason that evaluations (ultrasonography, computed tomography, etc.) to detect presence of an accessory are routinely performed in patients prior splenectomy. Nevertheless, despite preoperative investigations, routine examination may fail to detect an accessory spleen, or an accessory spleen may be overlooked during splenectomy. In addition, a resting accessory spleen may hyperthrophy post-splenectomy to compensate absence of primary splenic tissue. It has been hypothesized that, contamination of neighboring tissues with spleen cells during splenectomy may also cause the development of an accessory spleen [13]. Phom, et al. reported that accessory spleen was detected in 14 (31\%) of 45 ITP patients who experienced relapses post-splenectomy [14]. In another study, it is stated that the incidence of accessory spleen can be as high as $50 \%$ in cases of relapse after splenectomy [15]. ITP patients who develop relapse due to the presence of an accessory spleen respond to second splenectomy. Therefore, it is recommended that splenectomy be performed again in ITP patients with relapse due to accessory spleen.

Although the patient presented in this study experienced a relapse 3 months after splenectomy, it was only possible to detect accessory spleen after 6 years and at the third ultrasonographic examination. We concluded that the most important reason for detecting accessory spleen in repeat ultrasonographic examinations is associated with compensatory hypertrophy. In conclusion, in patients with ITP who develop relapse post-splenectomy, accessory spleen should be investigated and if the accessory spleen cannot be detected in initial examinations, due to inadequacy of testing methods and the operative skill of the technicians, it would be appropriate to continue the investigation of accessory spleen at close intervals and with persistency.

\section{References}

1. Nugent D, McMillan R, Nichol JL, Slichter SJ (2009) Pathogenesis of chronic immune thrombocytopenia: Increased platelet destruction and/or decreased platelet production. $\mathrm{Br} \mathrm{J}$ Haematol 146: 585-596.

2. Rodeghiero $F(2018) A$ critical appraisal of the evidence for the role of splenectomy in adults and children with ITP. Br J Haematol 181: 183-195.
3. Rodeghiero F, Stasi R, Gernsheimer T, Michel M, Provan D, et al. (2009) Standardization of terminology, definitions and outcome criteria in immune thrombocytopenic purpura of adults and children: Report from an international working group. Blood 113: 2386-2393.

4. Ghanima W, Godeau B, Cines DB, Bussel JB (2012) How I treat immune thrombocytopenia: The choice between splenectomy or a medical therapy as a second-line treatment. Blood 120: 960-969.

5. Cheng Y, Wong RS, Soo YO, Chui CH, Lau FY, et al. (2003) Initial treatment of immune thrombocytopenic purpura with high-dose dexamethasone. N Engl J Med 349: 831-836.

6. Wei Y, Ji XB, Wang YW, Wang JX, Yang EQ, et al. (2016) High-dose dexamethasone vs prednisone for treatment of adult immune thrombocytopenia: A prospective multicenter randomized trial. Blood 127: 296-302.

7. Mithoowani S, Gregory-Miller K, Goy J, Miller MC, Wang $G$, et al. (2016) High-dose dexamethasone compared with prednisone for previously untreated primary immune thrombocytopenia: A systematic review and meta-analysis. Lancet Haematol 3: e489-e496.

8. Schwartz J, Leber MD, Gillis S, Giunta A, Eldor A, et al. (2003) Long term follow-up after splenectomy performed for immune thrombocytopenic purpura (ITP). Am J Hematol 72: 94-98.

9. Vianelli N, Galli M, de Vivo A, Intermesoli T, Giannini B, et al. (2005) Efficacy and safety of splenectomy in immune thrombocytopenic purpura: Long-term results of 402 cases. Haematologica 90: 72-77.

10. Woo JH, Park SH, Park YK, Choi CB, Choi YY, et al. (2004) Postsplenectomy recurrence of thrombocytopenia with an accessory spleen. Korean J Intern Med 19: 199-201.

11. Portielje JE, Westendorp RG, Kluin-Nelemans HC, Brand A (2001) Morbidity and mortality in adults with idiopathic thrombocytopenic purpura. Blood 97: 2549-2554.

12. Budzynski A, Bobrzyński A, Sacha T, Skotnicki A (2002) Laparoscopic removal of retroperitoneal accessory spleen in patient with relapsing idiopathic thrombocytopenic purpura 30 years after classical splenectomy. Surg Endosc 16: 1636.

13. Leo CA, Pravisani R, Bidinost S, Baccarani U, Bresadola V, et al. (2015) Postsplenectomy recurrence of idiopathic thrombocitopenic purpura: Role of laparoscopic splenectomy in the treatment of accessory spleen. G Chir 36: 153157.

14. Phom H, Kumar A, Tripathi M, Chandrashekar N, Choudhry VP, et al. (2004) Comparative evaluation of Tc-99m-heatdenatured RBC and Tc-99m-anti-D IgG opsonized RBC spleen planar and SPECT scintigraphy in the detection of accessory spleen in postsplenectomy patients with chronic idiopathic thrombocytopenic purpura. Clin Nucl Med 29: 403-409.

15. Olsen WR, Beaudoin DE (1969) Increased incidence of accessory spleens in hematologic disease. Arch Surg 98: 762-763.

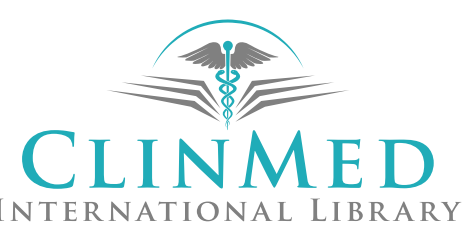

